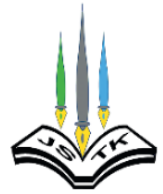

Stannum : Jurnal Sains dan Terapan Kimia

Website: https://journal.ubb.ac.id/index.php/stannum

doi: 10.33019/jstk.v3i2.2382

Research paper

\title{
Rice Flour Potential As Biodegradable Plate (Bioplastic) In Terms Of It's Characteristics
}

\section{Potensi Nasi Aking Sebagai Piring Biodegradable (Bioplastik) Ditinjau Dari Karakteristiknya}

\author{
Hamidah*, Hasan Marzuki, dan Nurul Kholidah \\ Department of Chemistry, Universitas of UIN Raden Fatah Palembang \\ * Corresponding author: hamidah.advan16@gmail.com
}

\begin{abstract}
ABSTRAK
Tepung beras merupakan biopolimer yang digunakan sebagai bahan utama pembuatan bioplastik (Biodegradable plate). Produk dibuat dari tepung beras dan buah belimbing wuluh (Averrhoa bilimbi L). Tujuan dari penelitian ini adalah untuk mengetahui pengaruh penambahan filtrat belimbing wuluh $(A$. bilimbi L) terhadap penyerapan air dan biodegradasinya. Penelitian ini menggunakan metode inversi fasa dengan variasi volume filtrat buah mulas (A. bilimbi L) sebanyak $10 \mathrm{ml}, 15 \mathrm{ml}, 20 \mathrm{ml}$, dan $25 \mathrm{ml}$. Hasil pembentukan biodegradable plate dengan penambahan filtrat belimbing ( $A$. bilimbi $\mathrm{L}$ ) menghasilkan warna coklat, tekstur keras, dan permukaan produk kasar. Hasil penelitian menunjukkan bahwa setiap penambahan volume filtrat belimbing wuluh (A. bilimbi L) dapat meningkatkan karakteristik resapan air dan biodegradasi masing-masing dengan persentase 48,29\%, 51,78 \%, 53,62\%, 55,27 \% dan 11,77\%, 24,52 \%, 28,42 \%, 36,88\%. Konfirmasi permukaan produk melalui scanning electron microscopy menunjukkan bahwa bioplastik yang dihasilkan memiliki susunan partikel yang kurang rapat dan terbentuknya pori-pori pada permukaan. Filtrat belimbing wuluh (A. bilimbi L) dapat digunakan dalam modifikasi karena mengandung senyawa yang bersifat asam lemah dengan $\mathrm{pH} 5$.
\end{abstract}

Kata Kunci: Tepung beras, belimbing wuluh (A bilimbi L), bioplastik, biodegradable plate

\section{PENDAHULUAN}

Industri petrokimia ialah industri yang bergerak di bidang pengolahan hasil minyak bumi. Dimana salah satunya menghasilkan produk polimerisasi (Sulistyono et.al, 2016). Produk polimerisasi dikenal masyarakat sebagai plastik. Penggunaan plastik dari minyak bumi telah banyak dimanfaatkan dalam memenuhi kebutuhan masyarakat di berbagai sektor mulai dari rumah tangga hingga industri. Namun dibalik peranannya dalam memenuhi kebutuhan, penggunaan plastik dapat meningkatkan keberadaan jumlah sampah plastik. Menurut Badan Pusat Statistik Lingkungan Hidup Indonesia, sampah plastik di Indonesia telah mengalami peningkatan sebesar 5,4 juta ton setiap tahunnya (Yordan et.al, 2015).

Peningkatan jumlah sampah plastik disebabkan kandungan polimernya memiliki sifat sulit terurai (Sinaga et.al, 2014). Jika penumpukan plastik terjadi secara terus menerus, dapat berakibat terjadinya pencemaran lingkungan. Adapun dampak negatif yang ditimbulkan antara lain rusaknya unsur hara di dalam tanah, mengurangi kualitas air, jika dibakar dapat menghasilkan emisi di 
udara, dan dapat menyebabkan banjir saat dibuang ke selokan (Karuniastuti et.al, 2013).

Plastik selain mencemari lingkungan penggunaanya sebagai bahan utama pembuatan piring dapat berbahaya bagi kesehatan jika digunakan secara tidak tepat. Hal ini dikarenakan sifatnya yang karsinogenik dan tidak tahan terhadap panas (Dewi et.al, 2018). Penggunanya dalam kondisi panas dapat menyebabkan kontaminasi dengan makanan. Kontaminasi makanan yang masuk ke dalam tubuh dapat mengakibatkan rusaknya jaringan tubuh manusia (Sulistyono et.al , 2016).

Dampak negatif yang ditimbulkan dari plastik, mendorong peneliti untuk berupaya mengurangi penggunaan plastik. Salah satu upaya yang dilakukan ialah mengembangkan bioplastik dari pati yang sifatnya dapat terdegradasi di alam dengan waktu yang lebih cepat (Ginting et.al, 2015). Jenis pangan dengan kandungan pati yang cukup besar adalah nasi. Nasi merupakan salah satu makanan pokok yang diproduksi hampir setiap hari di rumah tangga maupun tempat kuliner seperti restoran dan rumah makan. Berdasarkan survei yang dilakukan pada tanggal 17 Maret 2020, tercatat bahwa terdapat 12 tempat kuliner di Kelurahan D III Palembang, dapat menyisakan nasi dalam setiap harinya. Menurut pemilik tempat kuliner tersebut sisa nasi biasanya langsung dibuang atau tidak dilakukan pengolahan lanjut. Agar bermanfaat sisa nasi yang diperoleh di tempat tersebut dikeringkan menjadi nasi aking. Nasi aking inilah yang digunakan sebagai bahan utama dalam pembentukan piring biodegradable (Bioplastik).

Berbagai penelitian menyebutkan bahwa biopolimer pati perlu dilakukan modifikasi secara kimia untuk menghasilkan sifat atau karakteristik produk yang sesuai. Adapun karakteristik daya serap air pada produk bioplastik dapat ditingkatkan dengan menggabungkan biopolimer kitosan, gliserol, dan sagu (Kumoro et.al , 2014). Dalam proses modifikasi juga diperlukan penggunaan $\mathrm{CH} 3 \mathrm{COOH}$ sebagai pelarut (rusli dkk et.al, 2017). Namun penggunaan larutan $\mathrm{CH} 3 \mathrm{COOH}$ membuat bioplastik berbau menyengat (Selpiana et.al, 2015). Oleh Karena itu, dalam penelitian ini digunakan filtrat dari belimbing wuluh untuk memodifikasi. Belimbing wuluh mengandung senyawa asam lemah yang diharapkan mampu memodifikasi bioplastik dengan sifat yang lebih baik. Produk bioplastik berupa piring biodegradable yang terbentuk lalu diuji daya serap air dan biodegradasinya.
Pada Penelitian ini digunakan filtrat belimbing wuluh dengan berbagai variasi volume. Tujuannya untuk mengetahui pengaruh penambahan filtrat belimbing wuluh terhadap sifat kimiawi yang dihasilkan.

\section{METODOLOGI}

\section{Bahan}

Bahan yang digunakan dalam penelitian ini antara lain nasi sisa, sagu dan buah belimbing wuluh yang diperoleh di sekitaran kelurahan D III Palembang, gliserol Emsure ${ }^{\circledR}$, akuades secukupnya, kitosan Sigma-Aldrich, indikator $\mathrm{pH}$ universal dan media tanah andosol.

\section{Alat}

Alat yang digunakan dalam penelitian ini antara lain oven $U 055^{\circledR}$, penggiling, blender philp ${ }^{\circledR}$, kertas saring $1 \mu \mathrm{m}$, neraca analitik CP 214, batang pengaduk, gelas kimia Pyrex ${ }^{\circledR}$, gelas ukur Pyrex ${ }^{\circledR}$, statif, spatula, gelas erlemeyer Pyrex ${ }^{\circledR}$, termometer alkohol, corong buscher $42 \mathrm{~mm}$, pisau, spons berongga, seperangkat sieve shaker 40 sampai 120 mesh. pemanas listrik, Instrumentasi SEM tipe inspectS50 Phenom proX Desktop dan cetakan lingkaran berbahan aluminium dengan jari-jari $3 \mathrm{~cm}$.

\section{Prosedur}

\section{a. Pembuatan Tepung Nasi Aking}

Nasi sisa dibersihkan dari pengotor. Selanjutnya nasi dikeringkan menggunakan bantuan sinar matahari. Nasi yang telah kering digiling menggunakan Alat penggiling. Nasi aking lalu diayak menggunakan seperangkat sieve shaker dengan ayakan yang disusun mulai dari 40 hingga 120 mesh.

\section{b. Filtrasi Pada Buah Belimbing Wuluh}

Belimbing wuluh yang diperoleh dicuci dan dipotong. Selanjutnya belimbing wuluh di blender. Setelah itu dilakukan penyaringan agar filtrat dan kulit dari belimbing wuluh menjadi terpisah. Penyaringan filtrat dilakukan sebanyak 2 kali menggunakan kertas saring dan corong buscher. Kemudian $\mathrm{pH}$ Larutan belimbing wuluh diukur menggunakan indikator $\mathrm{pH}$ Universal.

\section{c. Pembentukan Piring Biodegradable}

8 gram tepung nasi aking dicampurkan ke dalam $10 \mathrm{ml}$ filtrat belimbing wuluh. Selanjutnya dilakukan pemanasan pada suhu 50 
${ }^{\circ} \mathrm{C}$. Saat filtrat masuk ke dalam permukaan nasi aking dilakukan penambahan 2 gram tepung sagu, 2 gram kitosan, dan $2 \mathrm{ml}$ gliserol. Selama proses pemanasan dilakukan pengadukan secara terus menerus hingga mencapai suhu $70^{\circ} \mathrm{C}$. Campuran biopolimer yang mulai memadat kemudian dicetak menggunakan cetakan berbentukan lingkaran. Setelah dicetak dilakukan pengeringan menggunakan oven pada suhu $30^{\circ} \mathrm{C}$ selama 30 menit. Sampel lalu di lepaskan dari cetakan dan didiamkan pada temperatur ruang. (Pembentukan piring biodegradable dilakukan dengan variasi filtrat dari belimbing wuluh $10 \mathrm{ml}, 15 \mathrm{~m}, 20 \mathrm{ml}$, dan 25 $\mathrm{ml}$ ).

\section{d. Pengujian Daya Serap Air}

Sampel ditimbang terlebih dahulu massa awalnya menggunakan neraca analitik. Kemudian sampel direndam dengan $50 \mathrm{ml}$ akuades selama 30 menit. Setelah proses perendaman sampel ditimbang kembali (Lazuardi et.al, 2013). Persentase daya serap air pada sampel dihitung menggunakan rumus dibawah ini

Daya serap air $(\%)=\frac{m_{2}-m_{1}}{m_{1}} \times 100 \%$

Keterangan :

$\mathrm{m}_{1}$ : massa sebelum perendaman (gram)

$\mathrm{m}_{2}$ : massa setelah perendaman (gram).

\section{e. Pengujian Biodegradasi}

Sampel ditimbang terlebih dahulu massa awalnya menggunakan neraca analitik. Selanjutnya sampel ditimbun ke dalam tanah. Ukuran tanah yang digunakan dalam pengujian ini adalah $50 \mathrm{~cm}$ x $50 \mathrm{~cm}$. Setelah 1 minggu sampel yang berada didalam tanah diambil dan ditimbang kembali (Selpiana et.al, 2015). Persentase biodegradasi pada sampel dihitung menggunakan rumus dibawah ini

Biodegradasi $(\%)=\frac{\mathrm{m}_{1}-\mathrm{m}_{2}}{\mathrm{~m}_{1}} \times 100 \%$

Keterangan :

$\mathrm{m}_{1}$ : massa sebelum ditimbun ke dalam tanah (g)

$\mathrm{m}_{2}$ : massa setelah ditimbun ke dalam tanah (g)

\section{f. Analisis Scanning Electron Microscopy (SEM)}

Sampel yang diujikan dengan variasi $10 \mathrm{ml}$ dan $25 \mathrm{ml}$. Adapun prosedur penggunaan instrumen SEM meliputi buka gas dengan memutar kran besi berlawanan arah jarum jam. Pasang steker UPS dan On kan UPS. Nyalakan SEM dengan menu menekan power dan layar PC. Setelah komputer menyala, tunggu sekitar 5

menit. Klik Vent untuk membuka chamber SEM, lalu masukkan sampel dan Klik Pump. Turunkan magnification-fokuskan gambar - atur WD ke15 MM sesuai kebutuhan. Fokuskan gambar dengan memutar WD pada control panel. Setelah mendapatkan gambar yang di inginkan, Klik Acquire untuk mengambil foto save gambar di folder yang diinginkan.

\section{HASIL DAN PEMBAHASAN}

Tabel 1 merupakan hasil pengamatan piring biodegradable (Bioplastik) dengan berbagai variasi volume filtrat belimbing wuluh.

Tabel 1. Hasil pengamatan piring biodegradable (Bioplastik)

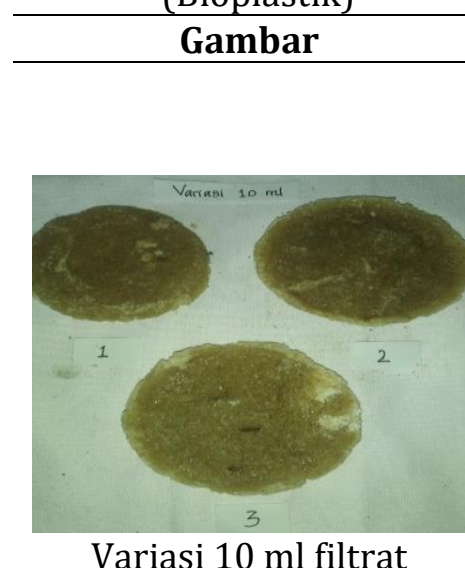

\section{Keterangan}

warna yang dihasilkan putih kecokelatan. Tekstur yang dihasilkan tidak terlalu keras. Permukaan yang dihasilkan kasar dan terdapat sedikit retakan pada bagian pinggir piring biodegradable.

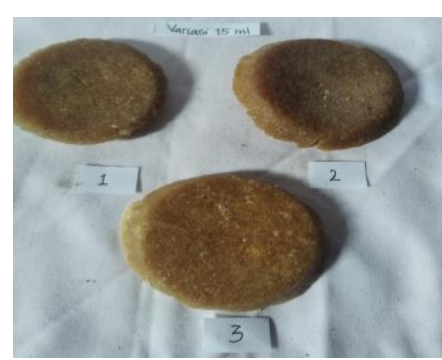

Variasi $15 \mathrm{ml}$ filtrat

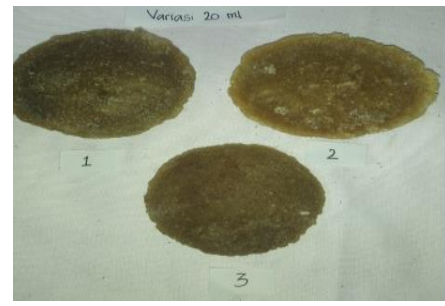

Variasi $20 \mathrm{ml}$ filtrat warna yang dihasilkan cokelat muda dan didapatkan bintik-bintik putih. Tekstur yang dihasilkan keras. Permukaan yang dihasilkan kasar.

warna yang dihasilkan cokelat pekat dan didapatkan bintik putih. Tekstur yang dihasilkan keras. Permukaan yang dihasilkan kasar. 


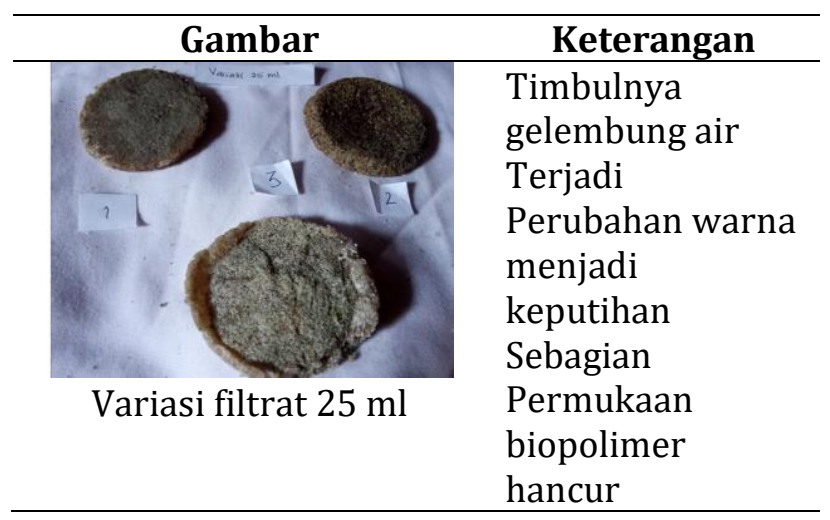

Hasil pengamatan menunjukkan bahwa penambahan filtrat belimbing wuluh dengan variasi 10, 15, 20, dan $25 \mathrm{ml}$ menghasilkan permukaan yang kasar dengan tekstur keras. Tekstur keras dari produk dapat disebabkan dari bahan biopolimer. Biopolimer dari kitosan, sagu dan nasi memiliki sifat yang keras dan kasar karena kemampuannya membentuk ikatan hidrogen antar rantai biopolimer (Yuliasih et.al, 2014). Warna kecokelatan dan kehitaman dihasilkan saat filtrat belimbing wuluh masuk ke dalam permukaan biopolimer. Adanya kandungan senyawa asam karboksilat dari belimbing wuluh memberikan warna kehijauan hingga kehitaman pada produk tergantung jumlah volume yang ditambahkan ke dalamnya. Semakin besar volume filtrat yang ditambahkan, warna yang dihasilkan pada produk akan semakin pekat (A. Rahmiati et.al, 2017).

\section{Karakteristik Daya Serap Air}

Karakteristik daya serap air dilakukan guna mengetahui kemampuan bioplastik dalam menyerap air. Gambar 1 menunjukkan pengaruh penambahan volume filtrat belimbing wuluh terhadap daya serap air produk bioplastik.

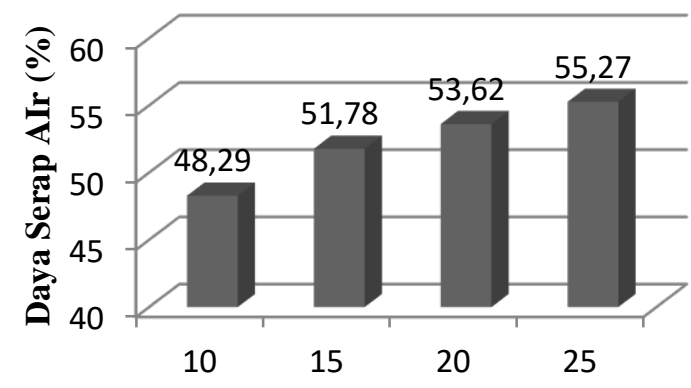

Volume Filtrat Belimbing Wuluh (ml)

Gambar 2. Pengaruh volume filtrat belimbing wuluh terhadap daya serap air
Hasil pengujian pada gambar 1 menunjukkan bahwa peningkatan daya serap air berbanding lurus dengan penambahan volume filtrat belimbing wuluh. Adanya penambahan volume filtrat belimbing wuluh akan meningkatkan ketersediaan molekul air dan asam karboksilat yang ada. Sehingga saat hidrolisis terjadi biopolimer nasi aking akan lebih banyak memutuskan ikatannya menjadi monomer. Jika jumlah monomer yang dihasilkan lebih banyak maka peluang tergantinya gugus $-\mathrm{OH}$ menjadi ester akan lebih besar. Berikut reaksi hidrolisis yang dapat terjadi pada produk bioplastik dapat dilihat pada gambar 2 .
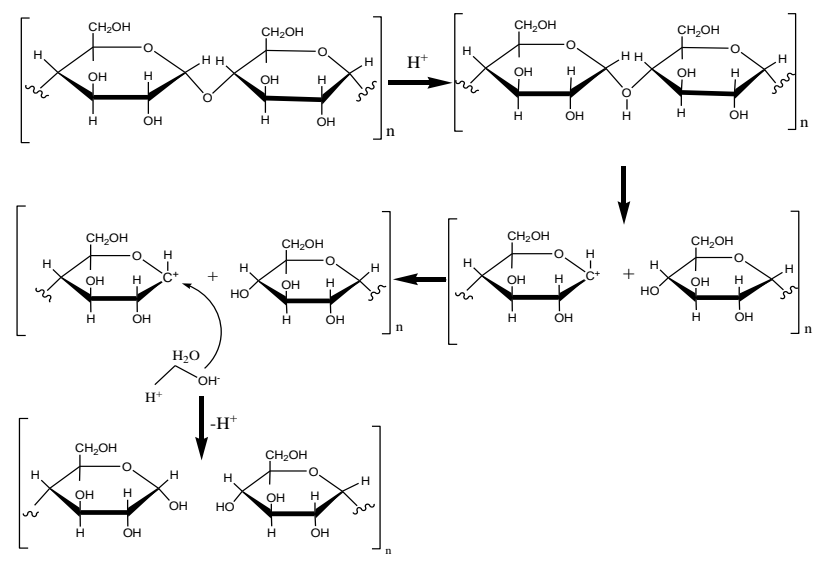

Gambar 3. Mekanisme hidrolisis biopolimer

Tergantinya gugus $-\mathrm{OH}$ menjadi ester mengurangi terbentuknya ikatan hidrogen. Berkurangnya ikatan hidrogen pada biopolimer mengakibatkan kekuatan ikatan antar molekul melemah dan jarak antar molekul semakin jauh. Jarak molekul yang jauh membuat biopolimer menjadi kurang rapat. Hal ini mengakibatkan molekul air akan lebih mudah masuk dan berinteraksi dengan biopolimer saat pengujian daya serap air dilakukan. Konsep tersebut sejalan dengan penelitian (Polnaya et.al, 2018), yang menyatakan bahwa ikatan hidrogen memiliki peranan dalam menentukan kekuatan ikatan pada biopolimer. Ikatan biopolimer yang lebih kuat cenderung membentuk struktur yang lebih teratur.

\section{Karakteristik Biodegradasi}

Karakteristik Biodegradasi dilakukan guna mengetahui kemampuan produk terurai di dalam tanah dalam kurun waktu 1 minggu. Gambar 2 menunjukkan pengaruh penambahan volume filtrat belimbing wuluh terhadap biodegradasi produk bioplastik. 


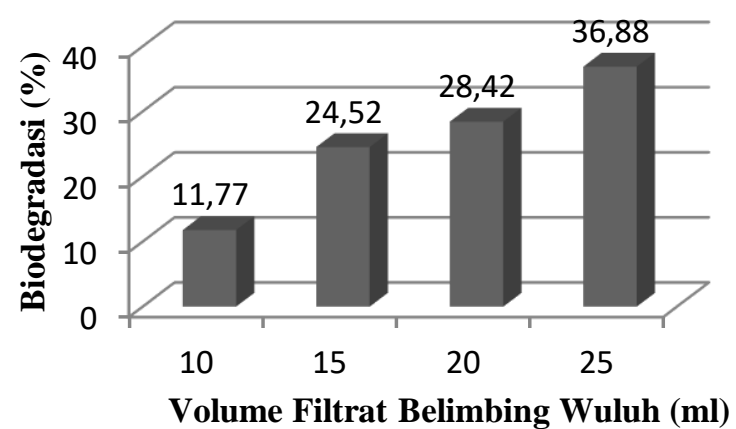

Gambar 4. Pengaruh volume filtrat belimbing wuluh terhadap Biodegradasi

Berdasarkan hasil pengujian pada gambar 2 menunjukkan bahwa penambahan volume filtrat belimbing wuluh dapat mempercepat biodegradasi. Hal ini dikarenakan penambahan filtrat menyebabkan ikatan antar molekul biopolimer akan semakin melemah. Ikatan biopolimer yang lemah akan mengalami pemutusan ikatan lebih cepat saat terkena radiasi sinar UV dari matahari (Suci et.al, 2019). Setelah ikatan antar molekul terputus gugus yang bersifat hidrofilik dari biopolimer seperti hidroksi dan ester, akan keluar dari rantai biopolimer dan terabsorbsi bersamaan dengan molekul air di dalam tanah. Proses absorbsi yang terjadi menyebabkan terjadinya pengurangan massa biopolimer serta membuat permukaan produk menjadi bergelembung. Berikut ini adalah reaksi biodegradasi yang dapat disebabkan oleh aktivitas mikroorganisme.

rantai karbon biopolimer $\stackrel{\text { aktivias mikroorananime }}{\longrightarrow} \mathrm{CH}_{4}+$ C.residu + biomassa $+\mathrm{H}_{2} \mathrm{O}$

Gambar 5. Reaksi biodegradasi biopolimer

Hal tersebut sejalan dengan penelitian Yuliasih, yang menyatakan bahwa saat berada didalam tanah gugus ester akan lebih cepat mengalami pemutusan ikatan dibandingkan ion hidroksida. Hal ini disebabkan ion hidroksida cenderung memiliki kemampuan lebih banyak membentuk ikatan hidrogen. Saat ikatan hidrogen yang terbentuk lebih banyak waktu yang dibutuhkan untuk memutuskan ikatannya akan lebih lama. Sehingga mengakibatkan laju biodegradasi juga menjadi lebih lama (Yuliasih et.al, 2014). Adanya aktivitas mikroorganisme juga menyebabkan terjadinya pengurangan massa produk. Dimana saat berada di permukaan produk mikroorganisme akan mengkonsumsi atom karbon dari rantai biopolimer yang mengakibatkan ikatan biopolimer menjadi terputus. Selanjutnya mikroorganisme akan mengeluarkan hasil metabolisme tubuhnya berupa biomassa maupun air (Nafianto et.al, 2019).

\section{Analisa Scanning Electron Microscopy (SEM)}

Pada penelitian ini digunakan instrumentasi SEM untuk menggambarkan permukaan produk bioplastik (piring biodegradable). Informasi yang di dapat berupa morfologi permukaan seperti bentuk permukaan dan susunan partikel pada permukaan. Berikut morfologi permukaan bioplastik pada variasi $10 \mathrm{ml}$ dan $25 \mathrm{ml}$ filtrat dapat dilihat pada gambar 6 dan 7 .

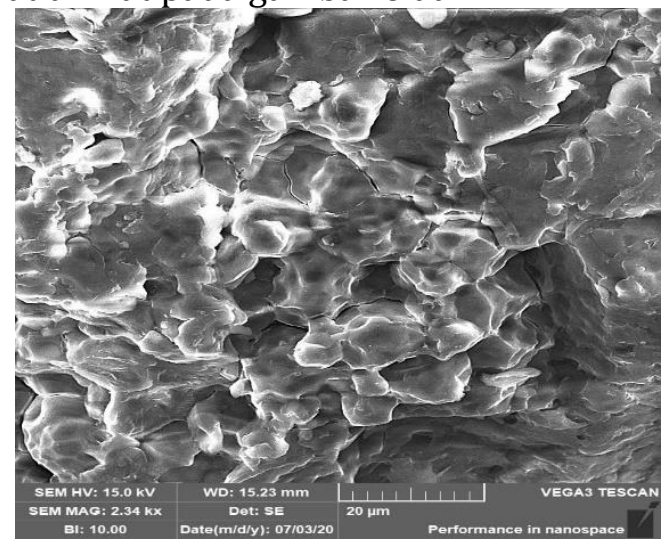

Gambar 6. Permukaan produk pada volume 10 ml filtrat belimbing wuluh

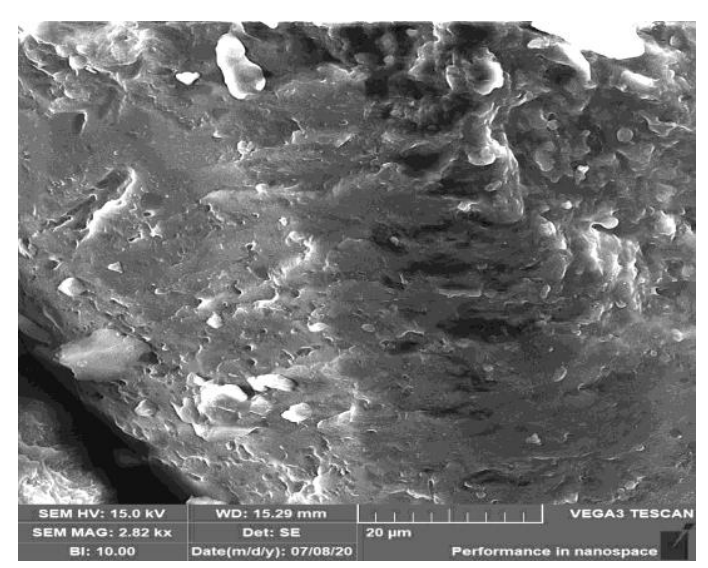

Gambar 7. Permukaan produk pada volume 25 $\mathrm{ml}$ filtrat belimbing wuluh

Pada penelitian ini Scanning electron microscopy memberikan informasi terkait susunan partikel dari permukaan produk. Konfirmasi permukaan yang ditunjukkan pada gambar 5 dan 6, memberikan informasi bahwa permukaan yang dihasilkan memiliki susunan partikel yang tidak teratur serta terbentuknya pori pada permukaan. Susunan partikel yang tidak teratur disebabkan adanya perbedaan ukuran partikel pada biopolimer yang mengakibatkan terbentuknya pori pada pada permukaan. Adanya pori yang dihasilkan memberikan peluang untuk molekul air masuk 
ke dalam permukaan biopolimer sehingga persentase kenaikan daya serap air.

Scanning electron microscopy juga memberikan informasi bahwa warna cerah yang ditampilkan dari permukaan menunjukkan atom karbon biopolimer dengan massa molekul lebih besar. Warna gelap menunjukkan susunan atom oksigen dan nitrogen dari biopolimer dengan massa molekul lebih rendah. Hal ini diasumsikan berdasarkan konsep eksitasi elektron dalam prinsip kerja SEM. Dimana senyawa yang mempunyai jumlah elektron yang lebih banyak membutuhkan energi yang tinggi dibutuhkan agar elektron bertumbukan. Hasil pemantulan elektron dengan energi tinggi akan di deteksi detektor SEM dengan warna permukaan yang cerah. Jika energi yang dibutuhkan lebih rendah dideteksi dalam bentuk permukaan lebih gelap (Diansari et.al, 2018).

\section{KESIMPULAN}

Kesimpulan penelitian yang dilakukan ialah filtrat dari buah belimbing wuluh dapat digunakan dalam memodifikasi biopolimer nasi aking secara hidrolisis. Dimana semakin besar penambahan volume filtrat dari buah belimbing wuluh memberikan peluang lebih besar untuk memperlemah ikatan hidrogen antar molekul biopolimer. Sehingga karakteristik daya serap air dan biodegradasi produk akan semakin meningkat.

\section{UCAPAN TERIMAKASIH}

Peneliti mengucapkan terimakasih kepada Laboratorium Terpadu Fakultas Sains dan Teknologi UIN Raden Fatah serta Laboratorium Forensik Polda Sumatera selatan yang telah menerima dan memberikan fasilitas dalam penelitian ini

\section{DAFTAR PUSTAKA}

Budiman, J., Nopianti, R, and Lestari S. D. (2018). Karakteristik Bioplastik dari Pati Buah Lindur (Bruguiera gymnorrizha). J. FishtecH. vol. 7 no.1. pp 49-59, 2018.

Dewi A. P. and Yesti, Y. (2018). Pemanfaatan Limbah Plastik Menjadi Kemasan Ramah Lingkungan Serta uji Biodegradasinya. JOPS J. Pharm. Sci., vol. 1, no. 2, pp. 33-38.

Diansari V,. Sundari, I., and Deswitri, N. (2018). Gambaran Scanning Electron Microscope
(SEM) Mikrostruktur permukaan Resin Komposit Nanofiler Setelah Perendaman Dalam Kopi Arabika Gayo. Cakradonya Dent. J. vol. 10, no. 2, pp. 96-101, 2018.

Hasanuddin, A., Rahim, A., Kadir, S. (2019). Modifikasi Pati Secara Asetilasi Terhadap Gugus Fungsi Asetil dan Kristanilitas Pati Ubi Banggai Asetat, Rekayasa, vol. 12, no. 2, pp. 135-140.

Kumoro, A. C. and Purbasari, A. (2014). Sifat mekanik dan morfologi plastik biodegradable dari limbah tepung nasi aking dan tepung tapioka menggunakan gliserol sebagai plasticizer. Teknik. vol. 35, no. 1, pp. 8-16.

Karuniastuti, N. (2013). Bahaya plastik terhadap kesehatan dan lingkungan," Swara Patra, vol. 3 , no. 1 .

Lazuardi, G. P. and Cahyaningru S. E. (2013). Pembuatan Dan Karakterisasi Bioplastik Berbahan Dasar Kitosan dan Pati singkong dengan Plasticizier Gliserol. UNESA J. Chem., vol. 2, no. 3.

Nafianto, I. (2019). Pembuatan Plastik Biodegradable dari Limbah Bonggol Pisang Kepok dengan Plasticizer Gliserol dan Minyak Jelantah. Integr. Lab J., vol. 7, no. 1 , pp. $75-89$

Rahmiati A, Darmawati, and Mukaromah, A. H. (2017). Daya Hambat Eksrak Etanol Buah Belimbing Wuluh (Averrhoa bilimbi L) Terhadap Pertumbuhan Staphylococcus aureus dan Staphylococcus epidermidis Secara in vitro. Prosiding Seminar Nasional \& Internasional. vol. 1.

Rusli, A., Metusalach, M., and Tahir, M. M. (2017). Characterization of Carrageenan Edible films Plasticized with Glycerol. J. Pengolah. Has. Perikan. Indones. vol. 20, no. 2, pp. 219-229.

Polnaya F. J., Huwae, A. A., and Tetelepta, G. (2018). Karakteristik Sifat Fisiko-Kimia dan Fungsional Pati Sagu Ihur (Metroxylon sylvestre) Dimodifikasi dengan Hidrolisis Asam. agriTECH vol. 38, no. 1 pp. 7-15.

Selpiana, S., Riansya, J. F., and Yordan, K. (2015). Pembuatan Plastik Biodegradable dari Tepung Nasi Aking. in Seminar Nasional Added Value of Energy Resources Avoer VII Proceeding. vol. 7, pp. 130-138.

Sinaga, R. F., Ginting, G. M., Ginting, M. H. S., and Hasibuan. (2014). Pengaruh Penambahan Gliserolterhadap Sifat Kekuatan Tarik Dan Pemanjangan Saat Putus Bioplastik Dari 
Pati Umbi Talas. J. Tek. Kim. USU. vol. 3 pp. 19-24.

Suci, R. (2019). "Karakteristik Bioplastik Berbahan Dasar Pati Ampas Sagu dan Pati Sagu (Metroxylon sp) dengan Penambahan Kitosan dari Berbagai Sumber," PhD Thesis, Universitas Andalas.

Sulistyono. S. (2016). Penggunaan Produk Plastik Dari Petrokimia dengan Bahan Dasar Minyak dan Gas Bumi Manfaat dan Bahayanya Bagi Kesehatan dan Lingkungan. Swara Patra. vol. 6, no. 2.

Yuliasih, I. and Sunarti, T. C. (2014). Pati sagu termodifikasi sebagai bahan starch-based plastics. in Prosiding Seminar Nasional Kulit, Karet dan Plastik. vol. 3.

Yulianti, R. and. Ginting, E. (2015). Perbedaan Karakteristik Fisik Edible Film dari Umbiumbian yang dibuat dengan Penambahan Plasticizer. J. Penelit. Pertan. Tanam. Pangan. vol. 31, no. 2, pp. 131-136. 